\title{
Changes in eukaryotic microbial communities of vernal pools along an urban-rural land use gradient
}

\author{
Sarah R. Carrino-Kyker ${ }^{1, *}$, Andrew K. Swanson², David J. Burke ${ }^{1,3}$ \\ ${ }^{1}$ Department of Biology, Case Western Reserve University, 2080 Adelbert Road, Cleveland, Ohio 44106-7080, USA \\ ${ }^{2}$ Phycal LLC, 51 Alpha Park, Highland Heights, Ohio 44143, USA \\ ${ }^{3}$ The Holden Arboretum, 9500 Sperry Road, Kirtland, Ohio 44094, USA
}

\begin{abstract}
Urban-rural gradients are important ecological settings to investigate how human land use impacts habitats and, indirectly, inherent organisms. Seasonally flooded vernal pools are common throughout temperate forest landscapes and may represent significant sites of forest nutrient cycling. The effects of urbanization on vernal pool microbial communities, important drivers of nutrient cycling, are largely unknown; thus studies to improve our understanding of microbes and their functional roles in these habitats are needed. Eukaryotic microbial communities sampled from 30 vernal pools of the Cuyahoga River watershed (USA), located along a gradient of urban land use, were profiled with denaturing gradient gel electrophoresis, and were compared between pools using nonmetric multidimensional scaling (NMS). Microbial diversity, and, specifically, the richness and diversity of the fungal operational taxonomic units (OTUs), increased with urbanization. Vernal pool eukaryotic microorganisms formed 2 NMS clusters that differed significantly in sub-watershed urban area. However, the significance of urbanization disappeared when fungal and algal communities were analyzed separately. Water conductivity was consistently correlated with different microbial communities (e.g. eukaryotic, fungal, and algal). Fungal communities also appeared related to the carbon content of the substrate, indicating that vegetation at a local scale may be important for community structure. Almost half of the OTUs matched fungal species, which provides taxonomic evidence that the eukaryotic microbial communities of vernal pools are dominated by fungal species. Overall, our data suggest that the eukaryotic microbes of vernal pools are influenced by a variety of factors of the surrounding landscape, including urbanization, water chemistry, and vegetation type.
\end{abstract}

KEY WORDS: 18S rDNA · Denaturing gradient gel electrophoresis · Diversity · Microbial communities $\cdot$ Vernal pools $\cdot$ Urbanization $\cdot$ Litter quality $\cdot$ Richness

\section{INTRODUCTION}

In the temperate regions of North America, seasonally flooded ponds, called vernal pools, are found throughout the landscape during the spring season. Similarly, vernal pools can be found on a variety of soil types, underlying geologies, and surrounding land uses (reviewed by Colburn 2004). For example, in a study of 106 vernal pools found in Amherst, Massachusetts (USA), Stone (1992) found that these pools were distributed on soil from 7 different drainage classes and of 6 different origins. Such differences in underlying material, accompanied by the variety of other factors that can change across the landscape, can lead to spatially variable water chemistry in vernal pools. In a study of 30 vernal pools of northeastern Ohio (USA), Carrino-Kyker \& Swanson (2007) found correlations between conductivity and the degree of agricultural land use and between water depth and the degree of urban area that surrounded the pools. In a smaller study of 4 vernal pools in Massachusetts, Brooks et al. (2002) also found an effect of urbanization on water 
chemistry. Specifically, these authors noted higher temperature, $\mathrm{pH}$, alkalinity, and conductivity in urban pools compared to non-urban pools. Such changes in the physical and chemical environment can affect members of the biological community, such as amphibians whose larval survival can be influenced by water chemistry (e.g. Freda \& Dunson 1985, Laposata \& Dunson 1998), insects whose development is strongly tied to the length of the hydroperiod (Brooks 2000), or microorganisms, which are perhaps the most environmentally-sensitive organisms on our planet due to their small size (McArthur 2006). This latter group of organisms has been particularly understudied in vernal pools.

Vernal pools are commonly known as sites of amphibian breeding and, as such, many studies on vernal pool ecology have focused on frogs or salamanders (reviewed by Colburn 2004). Much less attention has been given to the microbial communities of vernal pools, even though these communities are instrumental in ecosystem element cycling and energy flow in both terrestrial and aquatic habitats (Gutknecht et al. 2006, Liu et al. 2006). Vernal pools may represent 'hot spots' of nutrient cycling within the forest due to microbial processing of (1) allocthonous leaf litter inputs, which are colonized by microbes in both the dry and wet phases, and (2) the excrement and debris (e.g. exoskeletons) left behind by aquatic organisms that live in the pools (Williams 2006). The microorganisms of vernal pools comprise the base of the detrital-based food web upon which more complex organisms rely. Importantly, we do not have a clear understanding of what major taxonomic groups of microorganisms are present in these habitats, how the diversity of these communities is affected by water chemistry or urbanization, or the functional significance of these organisms in vernal pools. Carrino-Kyker \& Swanson (2008) conducted a study of 5 vernal pools over 3 mo and determined that both the bacterial and microbial eukaryotic communities changed rapidly over time, possibly as a consequence of changes in water chemistry and dominant abiotic conditions. This previous study, however, was done on a small scale; thus, the effects of landscape-level influences, such as urbanization and associated water chemistry changes, on these communities are largely unknown. Further, many other previous studies of vernal pool microbial communities were completed prior to the development of environmental genomic technologies (e.g. Bärlocher et al. 1978, Laird 1988).

In the current study, we examined the eukaryotic microbial communities in 30 vernal pools within a landscape of mixed land use types and utilized an urban-rural gradient to explore effects of urbanization on microbial communities in these pools (see Carrino-
Kyker \& Swanson 2007). Such urban-rural gradients are interesting settings to ask basic ecological questions, test theories, and contribute to ecosystem management (McDonnell \& Pickett 1990). Our study specifically addressed whether the eukaryotic microbial community was altered by changes in watershed land use, since there is conflicting evidence on whether urbanization affects the richness and diversity of eukaryotic microorganisms negatively (Jumpponen \& Jones 2009), positively (Dopheide et al. 2009), or has no effect (Cousins et al. 2003, Duong et al. 2007). We also sought to determine if and how the composition of the eukaryotic microbial community was affected by urbanization. As such, the eukaryotic microbial community was profiled using denaturing gradient gel electrophoresis (DGGE) and sequence analysis of excised bands, which allowed for relative comparisons of diversity and community composition based on partial 18S rDNAs.

\section{MATERIALS AND METHODS}

Field sampling and environmental parameters. In March 2004, 30 vernal pools in the Cuyahoga River Basin (near Cleveland, Ohio, USA) were sampled. The pools were located in 10 sub-watersheds $(\mathrm{n}=3$ pools per sub-watershed), which ranged in size from 359 to $4899 \mathrm{~km}^{2}$. The vernal pools were randomly located within the 10 sub-watersheds and were selected based on their existence in a deciduous forest. The percentage of each sub-watershed that represented a certain land use category was determined with digital maps (W.B. Clapham, Jr. pers. comm.) and a Geographic Information System (GIS; Fig. 1). The 10 sub-watersheds were selected to represent a gradient of urbanization (quantified as the sum of percent urban, percent suburban, and percent barren areas, which were mostly construction sites), but agricultural and natural land use classifications were also prevalent (Fig. 1). All 3 pools within a sub-watershed were located close to one another; therefore, they were similar distances from the nearest urban area (see Appendix 1). However, the urban-rural gradient reported here was quantified with a sub-watershed approach for 2 reasons: (1) subwatersheds are natural boundaries defined by water flow direction and accumulation, allowing the inclusion of any non-point source pollutants that could run off into the pools, and (2) land use features (e.g. construction sites, golf courses, industrial development) located close to the pools were not consistent across sites, making it difficult to conduct a consistent proximity analysis. A more thorough description of how sub-watersheds were delineated and how land use was assessed can be found elsewhere (Carrino-Kyker \& Swanson 2007). From each pool, 3 different sample 


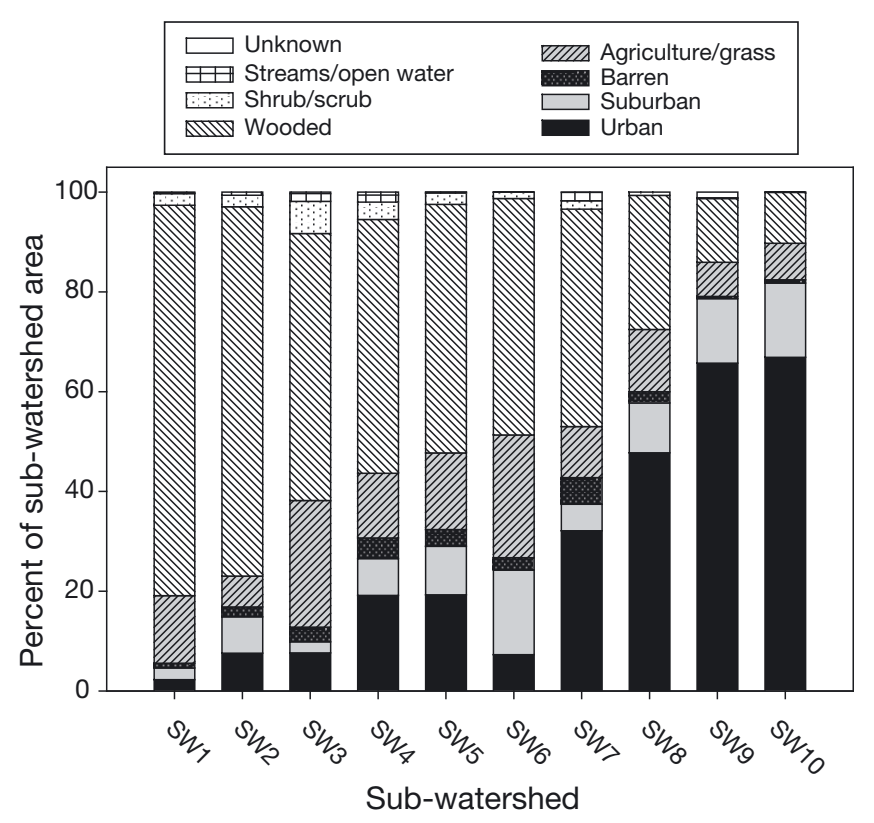

Fig. 1. GIS-characterized land use of 10 sub-watersheds of the Cuyahoga River Basin, Ohio, USA. Percent urbanization of each sub-watershed was defined as the sum of percent urban, percent suburban, and percent barren area (the lowest 3 categories on the bars). Sub-watershed (SW) numbers were assigned in order of decreasing percent natural area, which included percent wooded, percent shrub/scrub, and percent streams/open water (figure from Carrino-Kyker \& Swanson 2007). GIS: Geographic information system

types were taken $1 \mathrm{~m}$ from the edge of the pool. Sterile pipette tips were used to sample $1 \mathrm{ml}$ soil cores in triplicate, and leaf matter and water were sampled from 3 locations (ca. 3 leaves and $30 \mathrm{ml}$ of water at each location). Once in the laboratory, $50 \mathrm{ml}$ of the water sample were filtered through $0.2 \mu \mathrm{m}$ polycarbonate filters; no coarse filtering of the water was conducted. The environmental parameters of $\mathrm{pH}$, dissolved oxygen, temperature, and depth were measured in situ. Conductivity was determined on water samples that had been transported to the laboratory on ice after no longer than $7 \mathrm{~h}$. Specific descriptions of these measurements were given by Carrino-Kyker \& Swanson (2007). The leaves were sub-sampled 3 to 5 times and were used for percent carbon $(\% \mathrm{C})$, percent nitrogen $(\% \mathrm{~N})$, and $\mathrm{C}: \mathrm{N}$ with an elemental combustion system (Costech Analytical Technologies). These leaf tissue subsamples were representative of the collected leaves, such that they included tissue from each leaf type (i.e. species) found and more tissue from leaf types that were more abundant in the sample.

DNA extraction and PCR. DNA was extracted from each sample type (500 mg of soil, 5 leaves, and half of each water filter) using the Fast DNA ${ }^{\circledR}$ Spin Kit for Soil (MP Biomedicals) and following the manufacturer's protocol with the modifications described by CarrinoKyker \& Swanson (2008). Following the extractions, DNA from the 3 sample types was combined for each vernal pool (i.e. DNA was a composite of soil, litter, and water). Although there may be differences in the eukaryotic communities in these sample types (see CarrinoKyker \& Swanson 2008), the purpose of the present study was to examine how environmental changes affected the entire community of vernal pool organisms; therefore, the sample types were combined. Partial 18S rDNA was then PCR-amplified from these combined DNA samples using the primers and temperature cycling outlined by van Hannen et al. (1999), except that the final extension step was $30 \mathrm{~min}$ to eliminate DGGE double banding (Janse et al. 2004). The forward primer contained a GC clamp 5-'CGC CCG CCG CGC CCC GCG CCC GGC CCG CCG CCC CCG CCC C-3' on the 5' end (van Hannen et al. 1999). For each vernal pool sample, 4 DNA dilutions (1:5, $1: 10,1: 20$, and 1:40) were used in PCR reactions to limit bias (Chandler et al. 1997). The DNA concentration in each reaction ranged from 0.5 to $14.0 \mathrm{ng}$ between the 1:40 and 1:5 dilutions, respectively. The PCR reactions were $50 \mu \mathrm{l}$ in volume and contained $0.5 \mu \mathrm{M}$ of each primer, $200 \mu \mathrm{M}$ each dNTP, $1.5 \mathrm{mM} \mathrm{MgSO}_{4}$, and 1 unit of Platinum ${ }^{\circledR}$ Taq DNA Polymerase High Fidelity (Invitrogen) for an automatic 'hot start' to minimize nonspecific binding of the primers to non-target DNA. Amplifications were performed on an MJ Research PTC 100 Thermal Cycler.

DGGE and band profiling. Positive PCR reactions (of the 4 dilutions) for each vernal pool sample were combined equally to total $32 \mu \mathrm{l}$ for each vernal pool. These combined PCR products were subsequently loaded onto DGGE gels such that the concentrations ranged from approximately 0.4 to $2.0 \mu \mathrm{g}$ of PCR product for each vernal pool. Different DNA sequences present in this combined PCR sample were separated on $1 \mathrm{~mm}$ thick DGGE gels that were run for $16 \mathrm{~h}$, as described by van Hannen et al. (1999). We included a $2 \mathrm{~cm}$ stacking gel containing no denaturants through which samples were electrophoresed at $150 \mathrm{~V}$ until they entered the gradient gel (ca. $10 \mathrm{~min}$ ). Bands were visualized by staining with a 1:10000 dilution of SYBR gold (Molecular Probes) in $1 \times$ Tris Acetate EDTA for $40 \mathrm{~min}$ and photographed on the Foto Eclipse ${ }^{\mathrm{TM}}$ and Foto Analyst ${ }^{\circledR}$ (Fotodyne) gel doc system. Approximately 100 visualized bands from each DGGE gel were excised with sterile $1 \mathrm{ml}$ pipette tips. TotalLab ${ }^{\mathrm{TM}}$ gel analysis software (Nonlinear Dynamics) was used to identify distinct bands, determine band intensity (Rf value), calculate DNA quantity in each band by comparing Rf values in bands from the samples to bands of known DNA concentration, and cross compare operational taxonomic units (OTUs). 
DNA sequencing. One excised band representing each OTU was re-amplified as described above ('DNA extraction and PCR' section) with GC-clamped primers. These PCR products were then subjected to DGGE to confirm that each excised band represented a single sequence. Once the bands were visually pure, they were re-amplified with non-GC-clamped primers, purified with the QIAquick ${ }^{\circledR}$ PCR Purification Kit (QIAGEN), and sent for commercial DNA sequencing (MWG Sequencing) using the non-GC-clamped forward primer. The sequences were analyzed using the BLAST tool at the National Center for Biotechnology (NCBI) GenBank database (www.ncbi. nlm.nih.gov). If DGGE bands returned the highest similarity with an uncultured environmental sample, the next highest similarity to a biologically relevant species is reported here in order to provide a taxonomically meaningful result. The DGGE band sequences were deposited into GenBank under accession numbers GU459011 to GU459054. Sequences were viewed in Chromas Lite, Version 2.01 (Technelysium) and modified prior to submission such that bases labeled with ' $\mathrm{N}$ ' were replaced with more specific base codes following the IUPACIUB codes.

Data analysis and statistics. The relative abundance of each OTU in each sample was calculated using the Rf values generated with the TotalLab ${ }^{\mathrm{TM}}$ gel analysis software. Some faint bands in the DGGE gels had Rf values of 0 that were changed to 0.1 for analyses that included relative abundance. OTU richness per vernal pool was determined by counting the number of bands in each DGGE lane, and the Shannon-Weaver diversity index was calculated as described by Nübel et al. (1999). Pearson correlations between percent urban area and richness and diversity were conducted in SigmaStat, Version 3.5 (Systat Software). Changes in OTU patterns, including the presence/absence of OTUs and relative band intensity, were identified by performing the ordination technique of nonmetric multidimensional scaling (NMS) with PC-ORD, Version 5.0 (B. McCune and MJM Software). Like other ordination techniques, NMS provides a visual representation of the similarity between sites based on their community composition (i.e. on the resulting NMS graph, sites that cluster together show more overlapping taxa than sites that appear farther apart). Unlike other ordination techniques, NMS does not assume that the data are distributed normally and, as such, is appropriate for ecological data sets, which can be non-normal, arbitrary, and/or discontinuous (McCune \& Grace 2002). Even though the data for the present study were proportions, the raw data were used for the analyses reported here because an arcsine, square root transformation did not change the distribution of the data nor did it considerably alter the results. NMS clusters were determined visually after examining all possible graphs (including 2- and 3-dimensional graphs) from the resulting 3-dimensional solutions. A multi-response permutation procedure (MRPP) and indicator species analysis were performed on the NMS clusters, also in PC-ORD. MRPP was used to determine whether the clusters differed significantly in their OTU composition/abundance, and indicator species analysis was used to identify specific OTUs that were possibly driving the clustering pattern. To determine whether eukaryotic community patterns corresponded with the changing vernal pool environment, the general water quality parameters we measured were compared between the NMS clusters using $t$-tests (also conducted in SigmaStat). If data were not normally distributed, a Mann-Whitney rank sum test was used in place of a parametric $t$-test. The water chemistry data were also compiled in a secondary matrix which was correlated with the NMS axes in PC-ORD. The resulting Pearson correlation coefficients allowed further investigation of the relationship between environmental parameters and microbial community structure. Richness, diversity, and NMS analyses were conducted using all microbial eukaryotic OTUs, as well as the subset of OTUs that were only non-photosynthetic protists (labeled protist), only autotrophic protists (labeled algae), or only fungi. Graphs were made in SigmaPlot, Version 10.0 (Systat Software). NMS clusters were labeled with E1 and E2 for the NMS ordination of all microbial eukaryotes. Likewise, the algal and fungal NMS clusters were labeled A1 and A2 and F1 and F2, respectively.

\section{RESULTS}

DGGE revealed 47 OTUs in total from the 30 vernal pools. Successful DNA sequences were recovered from 44 of these OTUs, which were broadly organized into 3 major taxonomic groups: fungi, algae, and protists (Table 1). Of these 44 recovered sequences, $41 \%$ matched with fungal species, specifically the groups Ascomycota, Basidiomycota, and Chytridiomycota; $27 \%$ matched with protist species, specifically the groups Alveolata, Cercozoa, and Amoebozoa; and 23\% matched with algal species, specifically the groups Bacillariophyceae, Chrysophyceae, Synurophyceae, and Xanthophyceae (Table 1). Any sequences of macroscopic eukaryotes (shown in Table 1) were removed from further analyses. Three OTUs, which matched with protist sequences in the NCBI database, had low percent similarities (i.e. $<80 \%$ ). These OTUs were considered unknown eukaryotic microorganisms for the purpose of this study and were therefore not included in the calculations of protist richness or diversity. 
Table 1. Best-matched biologically relevant DNA sequence from the GenBank database for each excised operational taxonomic unit (OTU). Organisms with $<80 \%$ similarity were considered unknown microorganisms and, though they matched with protist sequences in the NCBI database, were not included in the calculations of protist richness or diversity

\begin{tabular}{|c|c|c|c|c|c|}
\hline OTU no. & $\begin{array}{l}\text { Band } \\
\text { Accession no. }\end{array}$ & Similarity (\%) & Database match & $\begin{array}{l}\text { t relative } \\
\text { Accession no. }\end{array}$ & Taxonomic description \\
\hline 1 & GU459011 & 79 & Entamoeba chattoni & AF149912 & Unknown \\
\hline 3 & GU459012 & 94 & Entamoeba chattoni & AF149912 & Protist (Amoebozoa) \\
\hline 5 & GU459013 & 77 & Xiphocephalus triplogemmatus & FJ459763 & Unknown \\
\hline $6^{\mathrm{a}}$ & GU459014 & 80 & Cruoria pellita & AY437664 & Rhodophyta \\
\hline 7 & GU459015 & 95 & Loxophyllum rostratum & DQ190465 & Protist (Alveolata; Cilophora) \\
\hline 8 & GU459016 & 79 & Amoeba leningradensis & AJ314605 & Unknown \\
\hline 9 & GU459017 & 98 & Navicula phyllepta & FJ40068 & Algae (Bacillariophyceae) \\
\hline 10 & GU459018 & 98 & Synura uvella & U73222 & Algae (Synurophyceae) \\
\hline 11 & GU459019 & 96 & Heteromita globosa & U42447 & Protist (Cercozoa) \\
\hline 12 & GU459020 & 97 & Spongomonas minima & AF411280 & Protist (Cercozoa) \\
\hline 13 & GU459021 & 96 & Navicula brockmannii & AM502020 & Algae (Bacillariophyceae) \\
\hline 14 & GU459022 & 98 & Navicula gregaria & AM501974 & Algae (Bacillariophyceae) \\
\hline 15 & GU459023 & 94 & Chilodonella uncinata & AF300283 & Protist (Alveolata; Cilophora) \\
\hline 17 & GU459024 & 95 & Mallomonas tonsurata & EF633325 & Algae (Synurophyceae) \\
\hline 18 & GU459025 & 93 & Spumella sp. & EF027354 & Algae (Synurophyceae) \\
\hline 19 & GU459026 & 96 & Hydrurus foetidus & FM955256 & Algae (Chrysophyceaee) \\
\hline 20 & GU459027 & 95 & Spumella sp. & AJ236858 & Algae (Synurophyceae) \\
\hline $21^{\mathrm{a}}$ & GU459028 & 97 & Phagocata sibirica & Z99948 & Platyhelminthes \\
\hline 22 & GU459029 & 94 & Chilodonella uncinata & AF300283 & Protist (Alveolata; Cilophora) \\
\hline 23 & GU459030 & 98 & Tribonema utriculosum & AM490826 & Algae (Xanthophyceae) \\
\hline 24 & GU459031 & 98 & Gomphonema angustatum & AM502005 & Algae (Bacillariophyceae) \\
\hline 25 & GU459032 & 91 & Lecythium sp. & AJ514867 & Protist (Cercozoa) \\
\hline 26 & GU459033 & 98 & Hypotrichida sp. & AF508777 & Protist (Alveolata; Cilophora) \\
\hline 27 & GU459034 & 95 & Oxytricha sp. & AF508769 & Protist (Alveolata; Cilophora) \\
\hline 28 & GU459035 & 95 & Chalara cylindrosperma & AF222507 & Fungi (Ascomycota) \\
\hline $29^{a}$ & GU459036 & 97 & Phagocata sibirica & Z99948 & Platyhelminthes \\
\hline 30 & GU459037 & 98 & Chalara constricta & AF222506 & Fungi (Ascomycota) \\
\hline 31 & GU459038 & 96 & Podosphaera tridactyla & AB022392 & Fungi (Ascomycota) \\
\hline 32 & GU459039 & 93 & Blyttiomyces helicus & DQ536491 & Fungi (Chytridiomycota) \\
\hline 33 & GU459040 & 88 & Chalara sessilis & AF222514 & Fungi (Ascomycota) \\
\hline 34 & GU459041 & 98 & Phialocephala sp. & EU155146 & Fungi (Ascomycota) \\
\hline 35 & GU459042 & 98 & Tetracladium sp. & FJ553447 & Fungi (Ascomycota) \\
\hline 36 & GU459043 & 96 & Microdochum nivale & AF548077 & Fungi (Ascomycota) \\
\hline 37 & GU459044 & 96 & Buellia georgei & AJ421681 & Fungi (Ascomycota) \\
\hline 38 & GU459045 & 98 & Madurella sp. & EU815932 & Fungi (Ascomycota) \\
\hline 39 & GU459046 & 88 & Pyrenochaeta lycopersici & DQ898289 & Fungi (Ascomycota) \\
\hline 40 & GU459047 & 96 & Ophiocordyceps sinensis & EF555097 & Fungi (Ascomycota) \\
\hline 41 & GU459048 & 98 & Thanatephorus cucumeris & DQ917659 & Fungi (Basidiomycota) \\
\hline $42^{\mathrm{a}}$ & GU459049 & 98 & Carallia brachiata & AM235548 & Viridiplantae; Magnoliophyta \\
\hline 43 & GU459050 & 98 & Aureobasidium pullulans & FJ023536 & Fungi (Ascomycota) \\
\hline 44 & GU459051 & 99 & Boletus rubropunctus & FJ480426 & Fungi (Basidiomycota) \\
\hline 45 & GU459052 & 95 & Thecotheus holmskjoldii & AF010589 & Fungi (Ascomycota) \\
\hline 46 & GU459053 & 98 & Myхоtrichum deflexum & AY541481 & Fungi (Ascomycota) \\
\hline 47 & GU459054 & 99 & Mrakia frigida & DQ831017 & Fungi (Basidiomycota) \\
\hline
\end{tabular}

At higher urbanized sites, both richness and diversity were not eroded (Fig. 2). In fact, vernal pools in more urbanized sub-watersheds had higher eukaryotic diversity (Fig. 2b). Eukaryotic diversity had a significant positive correlation with percent urban area (Pearson correlation coefficient $=0.523 ; \mathrm{p}<0.01)$. Similarly, there were positive trends in richness and diversity of fungal OTUs with urbanization (Fig. 2c,d). Both fungal richness (Pearson correlation coefficient =
0.497; p < 0.01) and fungal diversity (Pearson correlation coefficient $=0.540 ; \mathrm{p}<0.01$ ) were significantly positively correlated with percent urban area. No significant correlations were found between percent urban area and eukaryotic richness, algal richness or diversity, or protist richness or diversity.

Community composition in the vernal pools varied between the sub-watersheds. For all eukaryotic OTUs, the vernal pools formed 2 fairly distinct clusters in the 

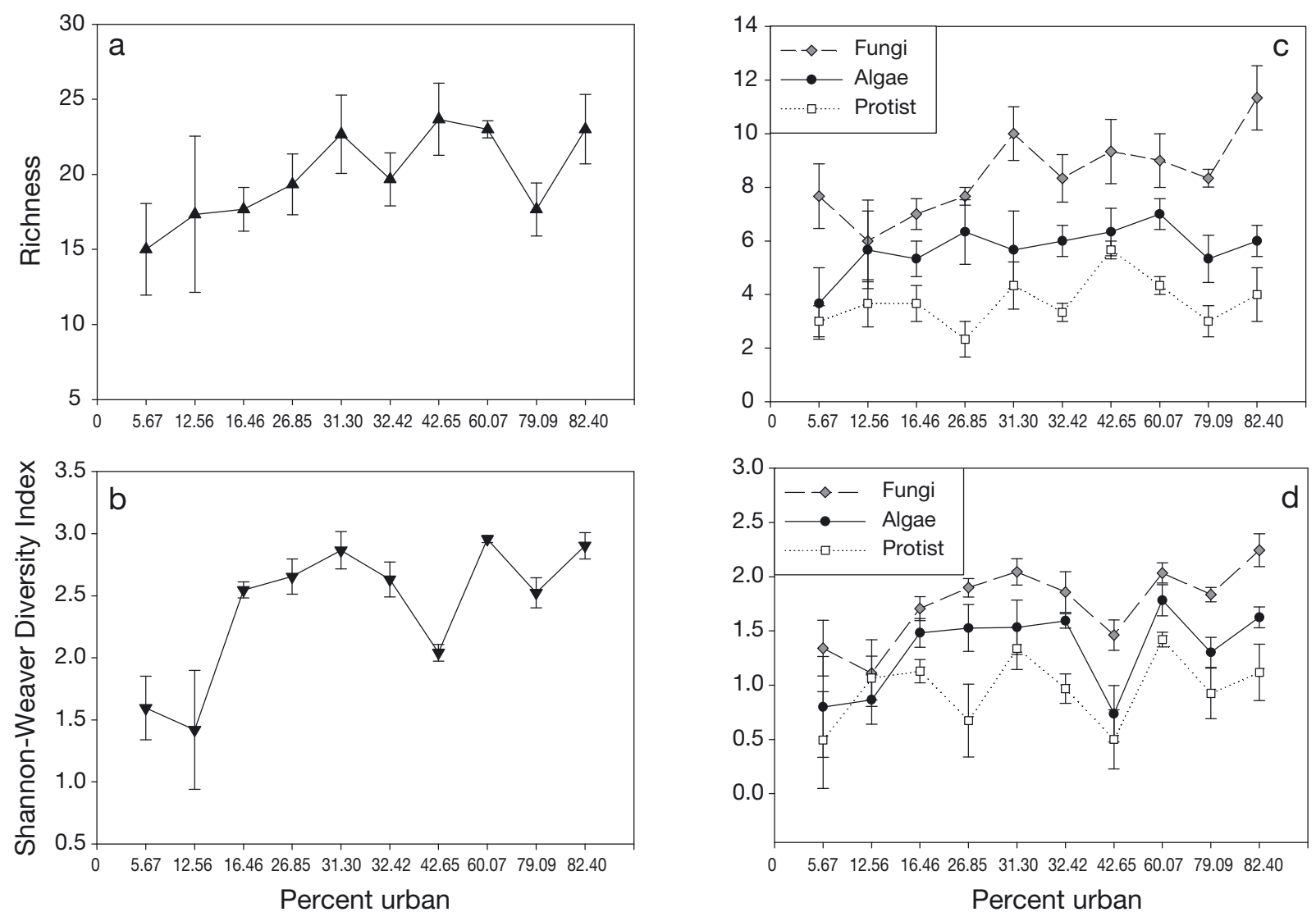

Fig. 2. Average richness and Shannon-Weaver diversity $( \pm \mathrm{SE})$ of $(\mathrm{a}, \mathrm{b})$ the entire eukaryotic community and of $(\mathrm{c}, \mathrm{d})$ the subset of operational taxonomic units that were fungi, algae, or protists found in 30 vernal pools across a gradient of urbanization. Vernal pools were located in 10 sub-watersheds with differing degrees of percent urban area ( $\mathrm{n}=3$ pools per sub-watershed). Richness and diversity were determined with denaturing gradient gel electrophoresis

NMS ordination (Fig. 3a) that were shown to be significantly different by MRPP $(\mathrm{p}<0.001)$. The vernal pools in these 2 clusters differed significantly in their surrounding urbanization $(\mathrm{p}=0.036)$ and dissolved oxygen $(p=0.029)$, with cluster E1 pools having a lower percent urban area and higher dissolved oxygen concentration (Table 2). We also found a significantly lower $\mathrm{C}: \mathrm{N}$ ratio in the leaves in cluster E1 pools $(\mathrm{p}=$ 0.037; Table 2). The dimensions of the eukaryotic NMS were strongly correlated (i.e. Pearson correlation coefficients $\geq 0.296$ ) with the water chemistry variables of temperature and conductivity, the $\% \mathrm{C}$ content of the leaves, and all land use categories (Table 3). Several OTUs were found to be significant indicators of the clusters with indicator species analysis. One algal sequence (OTU 9) was a significant indicator of cluster E2 communities (Table 2). Protist sequences OTU 11 and OTU 26 were significant indicators of clusters E1 and E2, respectively (Table 2). Two fungal OTUs (numbers 34 and 38) were significant indicators for cluster E1, while cluster E2 had only 1 significant fungal indicator: OTU 35 (Table 2).
When the individual groups were analyzed with NMS, both the fungi and the algae showed a cluster pattern (Fig. 3b,c; a reliable NMS diagram was not generated with protist data). The fungal clustering was similar to the overall eukaryotic clustering, suggesting that the fungi may be strongly affecting the overall eukaryotic NMS. MRPP also showed these clusters to be significantly different $(p<0.001)$. The vernal pools in the fungal clusters differed in their conductivity $(\mathrm{p}=$ $0.001)$ and $\% C$ content of the leaves $(p=0.002)$, both which were lower in cluster F1 (Table 2). Further, the $\% \mathrm{C}$ of leaves and water conductivity, along with water temperature and dissolved oxygen, were strongly correlated with fungal NMS dimensions (Table 3). There were several significant indicator OTUs for the fungal clusters, all of which matched with sequences in the group Ascomycota (Tables $1 \& 2$ ). The clustering of the algal NMS diagram showed that 6 pools differed significantly from the rest in their composition of algae ( $p<0.001$ with MRPP analysis). Only conductivity was significantly different between the algal clusters $(p=$ 0.022 ) and was lower in cluster A2 pools (Table 2). 

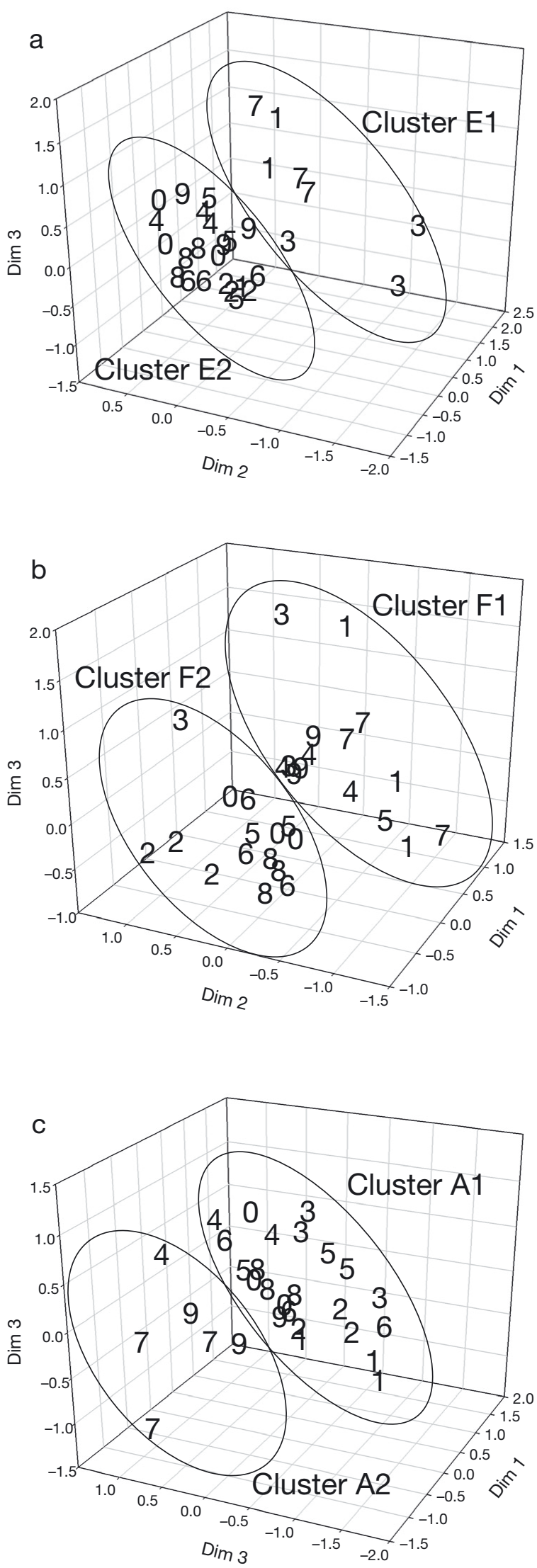

When the algal NMS dimensions were correlated with the secondary matrix, water temperature and dissolved oxygen, leaf \% $\mathrm{C}$ and $\mathrm{C}: \mathrm{N}$, and all land use categories were strongly correlated (Table 3 ). For the algal NMS, significant indicators were OTUs 18 and 20 for cluster A1, and OTUs 19 and 23 for cluster A2 (Table 2).

\section{DISCUSSION}

The primary aim of this study was to determine whether relative differences in eukaryotic microbial community structure in vernal pools varied with urbanization at a landscape scale. We observed an increase in microbial diversity and, specifically, in fungal richness and diversity with increasing urbanization. The lack of eroded richness and diversity with human impact suggests that vernal pool microorganisms, which are tolerant of the naturally varying environmental conditions of an ephemeral habitat (CarrinoKyker \& Swanson 2007, 2008), may not experience decreased diversity with urbanization. In some studies where macroscopic organisms were surveyed, a positive relationship between human population density and species richness was found (Balmford et al. 2001, reviewed by Arújo 2007). It has been argued, at least for macroscopic organisms, that this positive relationship is due to the fact that humans, along with many other species, benefit by living in regions of high environmental heterogeneity (Luck 2007, Hugo \& van Rensburg 2008). Urbanization may be increasing habitat heterogeneity in vernal pools, in both space and time, resulting in higher levels of diversity. Studies of stream bacterial (Cody et al. 2000) and ciliate (Dopheide et al. 2009) communities also found higher richness and diversity at sites more impacted by human activity. It is plausible that in urbanized watersheds, increased nutrient runoff and changes in water chemistry following storm events create greater temporal heterogeneity in aquatic habitats, leading to increases in overall microbial diversity. Forest fragmen-

Fig. 3. Three-dimensional nonmetric multidimensional scaling (NMS) ordination diagrams showing the similarity between the vernal pool (a) eukaryotic community, (b) fungal community, and (c) algal community. Stress values for each NMS were $13.70 \%$ for the eukaryotic ordination (a), $13.78 \%$ for the fungal ordination (b), and $11.34 \%$ for the algal ordination (c). Each pool is represented by a number indicating the sub-watershed within which that pool was located. On each graph are 2 clusters which are identified by circles and labeled with an E, F, or A for the eukaryotic, fungal, and algal NMS ordinations, respectively. Clusters were visually determined and found to be significantly different in their community structure with a multi-response permutation procedure. Dim: NMS dimension 


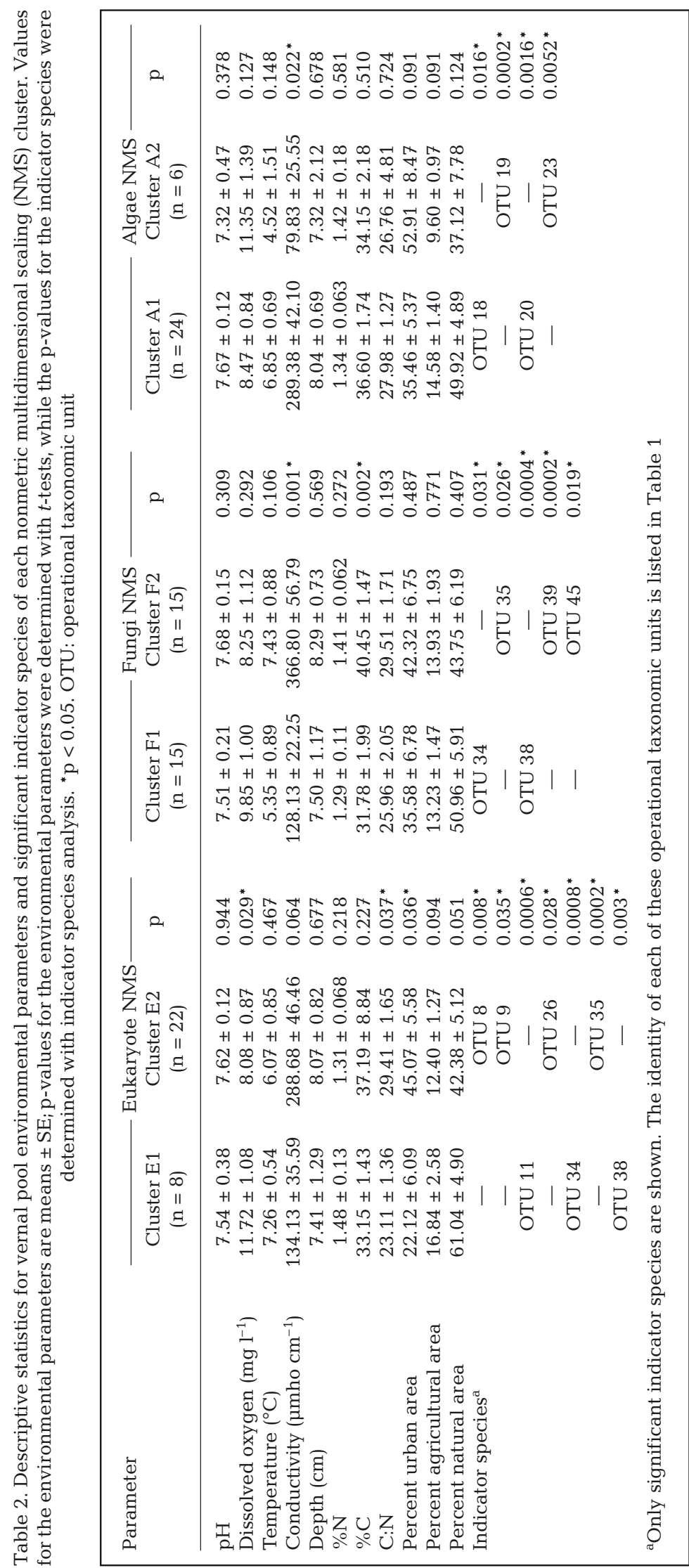

tation and plant community changes in urban watersheds could also create spatial variability across a vernal pool in terms of light availability and water temperature, leading to greater within-pool heterogeneity and microbial diversity. For microorganisms, however, it may be that the effect of urbanization on richness and diversity is specific to different habitats or regions. Indeed, others have noted a decrease (e.g. Jumpponen \& Jones 2009) while a greater number of other studies have found no change in microbial richness and diversity with anthropogenic pollutants (e.g. Dorigo et al. 2002, Cousins et al. 2003, Duarte et al. 2004, Duong et al. 2007, Borin et al. 2009). Although metrics of richness and diversity can be useful, when applied to microbial communities, they are often insensitive to environmental changes (Morris \& Blackwood 2007); thus the effects of urbanization reported here may be more strongly impacting microbial community composition.

It is more common that microbial communities change in their taxonomic composition with human impacts, which has been consistently documented in scientific literature (e.g. Cody et al. 2000, Dorigo et al. 2002, Cousins et al. 2003, Duarte et al. 2004, Duong et al. 2007, Borin et al. 2009, Dopheide et al. 2009). We also found that the community composition of eukaryotic microbes in vernal pools was related to the percent of each subwatershed that was urban area. This observation is likely due to the fact that some species of protists, algae, and fungi are better adapted to the environmental conditions created by urbanization than others. That each eukaryotic cluster resulting from the NMS ordination had significant indicator OTUs associated with them lends support to the conclusion that some species are better adapted to the urban pools than others. This is further supported by the observations that the eukaryotic community structure was significantly affected by dissolved oxygen concentration, while the fungal and algal community structures were significantly affected by conductivity. These general water quality characteristics are known to be influenced by urbanization, with more impacted aquatic habitats often experiencing lower dissolved oxygen concentration and higher conductivity due to polluted runoff from developed areas (Daniel et al. 2002, Miserendino et al. 2008). 
Table 3. Pearson correlation coefficients showing the relationship between vernal pool characteristics (e.g. water chemistry, substrate litter quality, and sub-watershed land use) and nonmetric multidimensional scaling (NMS) dimensions (labeled Dim). NMS was performed for the entire eukaryotic microbial community (Eukaryote) as well as the portion of the community identified as fungi (Fungi) or autotrophic protists (Algae). Because our study had $n=30$, strong correlations were identified as a Pearson correlation coefficient $\geq 0.296$ (Zar 1999)

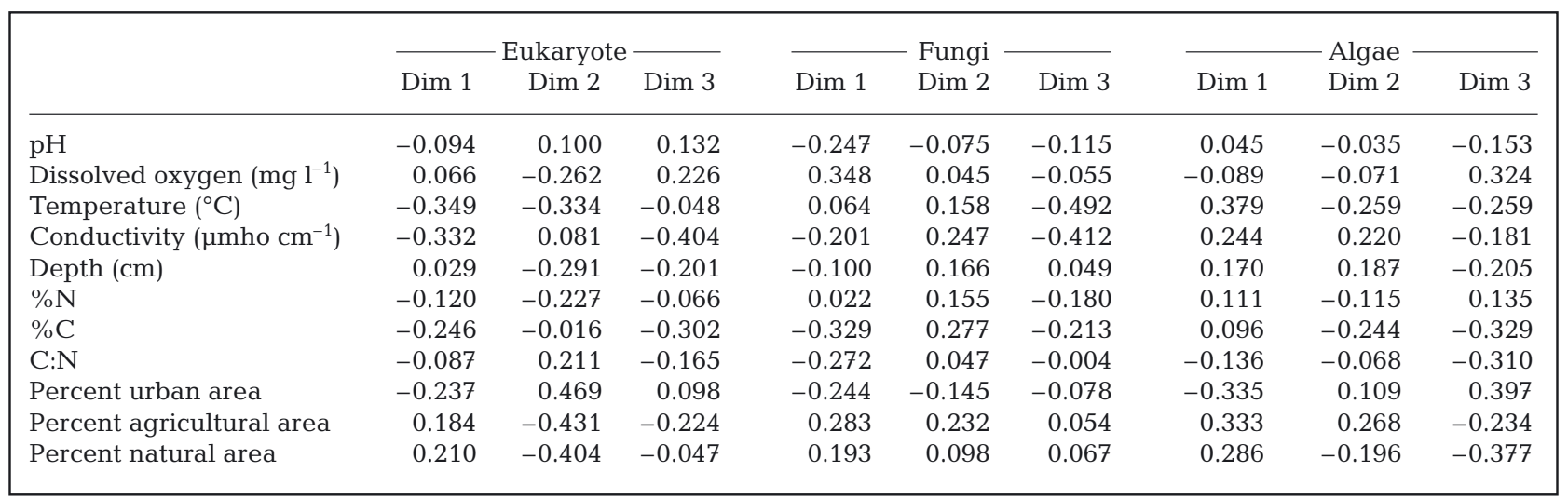

The importance of dissolved oxygen and conductivity for eukaryotic microbes was also shown by the indicator species analysis. Of the 7 indicator OTUs between the eukaryotic NMS groups, 3 were protists and 3 were fungi. In aquatic habitats, dissolved oxygen is of paramount importance for the distribution of microbial eukaryotes; for example, aquatic fungi are reliant on dissolved oxygen to carry out decomposition with different species thriving in high versus low oxygen conditions (Medeiros et al. 2009). In vernal pools, the conductivity likely includes measures of essential nutrients, namely phosphorus and nitrogen ions, which are often high in urban runoff (Carpenter et al. 1998). These nutrients are important determinants for the survival of different algal and fungal species. Phosphorus availability is particularly important for the distribution of golden-brown algae (Wetzel 2001), which comprise 3 of the 4 significant OTUs for the algal NMS groups. Nutrient availability is also important for the decomposition activity of aquatic fungi (Gulis et al. 2006), and all significant OTUs for the fungal NMS groups were in the Ascomycota, a group that contains over $90 \%$ of all aquatic hyphomycetes (Webster 1992). Vernal pool conductivity can also be related to increased salt content in runoff from road deicing agents (Karraker et al. 2008), and certain algal and fungal species may be more tolerant of these high salt levels.

It is worthwhile to note that urbanization is not the only factor known to affect dissolved oxygen or conductivity, and other characteristics of the landscape may be important for vernal pools, as urbanization was no longer a significant factor in structuring the fungal and algal communities when they were examined alone. For example, conductivity can be affected by soil type that varies across the landscape (Wierenga et al. 1969). In the same 30 pools used in the current study, agricultural land use was found to influence conductivity (Carrino-Kyker \& Swanson 2007). Although percent agriculture was not significantly different between any of the NMS clusters in the current study, it was strongly correlated with both eukaryotic and algal NMS dimensions. Water temperature, which we found consistently correlated with NMS dimensions, affects the dissolved oxygen content of water (Wetzel 2001) and can vary in shallow water bodies at multiple scales (e.g. spatially across a landscape as wetland area changes, Li et al. 2009; or temporally as air temperatures rise and fall, over the course of a day, Podrabsky et al. 1997, or season, Bonner et al. 1997). Regardless of the factors responsible for the change, our data indicate that the composition of eukaryotic microorganisms in vernal pools varied with urbanization at a landscape scale, and such a change in microbial community composition may have important consequences for ecosystem function (Kinzig et al. 2001, Loreau et al. 2002, Morin \& McGrady-Steed 2004), which should be explored in future studies of these habitats.

Our results also suggest that local site-specific characteristics may be just as important as urbanization in structuring the eukaryotic community of vernal pools. We found the OTU composition of eukaryotic and fungal communities to be significantly influenced by litter quality, and at least 1 dimension resulting from the eukaryotic, fungal, and algal NMS ordinations was strongly correlated with at least 1 aspect of litter quality. Similarly, Cousins et al. (2003) found that the structure of arbuscular mycorrhizal fungi was influenced by vegetation type just as much as by land use. Further, Ochimaru \& Fukuda (2007) found that the richness of fungi involved in decomposition was higher in urban forests compared to rural forests and suggested that 
this was due to differential litter distribution, not the effects of land use. Contrary to our findings, Verb et al. (2001) saw little change in algal community structure with different vegetative litter substrates in a mesocosm study after $56 \mathrm{~d}$. However, in their study, Verb et al. (2001) used fairly coarse groups of vegetation with mixed deciduous forest substrate comprising 1 group. We argue that changes in litter quality on a finer scale (e.g. between different species of trees that comprise the deciduous forest) may be important, as qualitative data we collected using canopy pictures over the pools suggest that the main sources of leaf litter into cluster E1 and F1 pools were Acer trees, which are relatively easily decomposed, while the canopy trees over cluster E2 and F2 pools contained higher numbers of Fraxinus, Quercus, Platanus, and Populus leaves (data not shown). Thus, in landscape-scale studies, the vegetation at a more local scale cannot be ignored, as litter quality can affect both community structure as well as ecosystem function (Alarcón-Gutiérrez et al. 2009, Kotilainen et al. 2009, Ndaw et al. 2009). Our observation that the majority of OTU sequences were saprotrophic fungi, which are involved in the decomposition of allochthonous leaf litter into vernal pools, provides further support that litter quality and local environmental factors are important for vernal pool microbial community structure. Future studies should explore the influence of leaf litter composition and quality on vernal pool microbial communities, as they appear to play a role in structuring these communities that form the basis of the aquatic food web, but were not quantitatively measured in the current study.

Overall, we found that urbanization was associated with an increase in microbial richness and diversity and an altered microbial community composition in vernal pools. This suggests that there is a suite of eukaryotic microbial species which are able to tolerate the fluctuations in water chemistry associated with urbanization and are likely aided by their adaptations to the ephemeral environment of vernal pools. These changes in microbial community composition may also influence ecosystem function, and future studies should investigate this. Urbanization was not the only factor found to affect microbial community composition. Litter quality and other local water chemistry changes may be just as important as larger landscapescale influences on vernal pool microbial communities. Therefore, when conducting landscape-scale studies, local effects on the microbial community cannot be ignored, as they may be equally important for structuring microbial communities to landscape variability.

Acknowledgements. We thank Cuyahoga Valley National Park, Cleveland Metroparks, and Metro Parks Serving Summit County for allowing us to sample on their property, J.
Bader for lending us sampling equipment, A.M. Gorman and A. Holstein for help with GIS, and. W. B. Clapham and M. Sullivan for providing land use maps. We also appreciate the helpful comments of K. Smemo, C. Blackwood, and 2 anonymous reviewers.

\section{LITERATURE CITED}

Alarcón-Gutiérrez E, Floch C, Augur C, Le Petit J, Ziarelli F, Criquet S (2009) Spatial variations of chemical composition, microbial functional diversity, and enzyme activities in a Mediterranean litter (Quercus ilex L.) profile. Pedobiologia 52:387-399

Araújo MB, Rahbek C (2007) Conserving biodiversity in a world of conflicts. J Biogeogr 34:199-200

Balmford A, Moore JL, Brooks T, Burgess N, Hansen LA, Williams P, Rahbek C (2001) Conservation conflicts across Africa. Science 291:2616-2619

Bärlocher F, Mackay RJ, Wiggins GB (1978) Detritus processing in a temporary vernal pool in southern Ontario. Arch Hydrobiol 81:269-295

> Bonner LA, Diehl WJ, Altig R (1997) Physical, chemical and biological dynamics of five temporary dystrophic forest pools in central Mississippi. Hydrobiologia 353:77-89

Borin S, Brusetti L, Daffonchio D, Delaney E, Baldi F (2009) Biodiversity of prokaryotic communities in sediments of different sub-basins of the Venice lagoon. Res Microbiol 160:307-314

Brooks RT (2000) Annual and seasonal variation and the effects of hydroperiod on benthic macroinvertebrates of seasonal forest ('vernal') ponds in central Massachusetts, USA. Wetlands 20:707-715

Brooks RT, Miller SD, Newsted J (2002) The impact of urbanization on water and sediment chemistry of ephemeral forest pools. J Freshw Ecol 17:485-488

Carpenter SR, Caraco NF, Correll DL, Howarth RW, Sharpley AN, Smith VH (1998) Nonpoint pollution of surface waters with phosphorus and nitrogen. Ecol Appl 8:559-568

Carrino-Kyker SR, Swanson AK (2007) Seasonal physicochemical characteristics of thirty Northern Ohio temporary pools along gradients of GIS-delineated human landuse. Wetlands 27:749-760

Carrino-Kyker SR, Swanson AK (2008) Temporal and spatial patterns of eukaryotic and bacterial communities found in vernal pools. Appl Environ Microbiol 74:2554-2557

Chandler DP, Fredrickson JK, Brockman FJ (1997) Effect of PCR template concentration on the composition and distribution of total community $16 \mathrm{~S}$ rDNA clone libraries. Mol Ecol 6:475-482

Cody DG, Heath RT, Leff LG (2000) Characterization of benthic bacterial assemblages in a polluted stream using denaturing gradient gel electrophoresis. Hydrobiologia 432:207-215

Colburn EA (2004) Vernal pools: natural history and conservation. The McDonald and Woodward Publishing Company, Blacksburg, VA

Cousins JR, Hope D, Gries C, Stutz JC (2003) Preliminary assessment of arbuscular mycorrhizal fungal diversity and community structure in an urban ecosystem. Mycorrhiza 13:319-326

> Daniel MHB, Montebelo AA, Bernardes MC, Ometto JPHB and others (2002) Effects of urban sewage on dissolved oxygen, dissolved inorganic and organic carbon, and electrical conductivity of small streams along a gradient of urbanization in the Piracicaba River basin. Water Air Soil Pollut 136:189-206 
Dopheide A, Lear G, Stott R, Lewis G (2009) Relative diversity and community structure of ciliates in stream biofilms according to molecular and microscopy methods. Appl Environ Microbiol 75:5261-5272

Dorigo U, Bérard A, Humbert JF (2002) Comparison of eukaryotic phytobenthic community composition in a polluted river by partial $18 \mathrm{~S}$ rRNA gene cloning and sequencing. Microb Ecol 44:372-380

> Duarte S, Pascoal C, Cássio F (2004) Effects of zinc on leaf decomposition by fungi in streams: studies in microcosms. Microb Ecol 48:366-374

> Duong TT, Feurtet-Mazel A, Coste M, Dang DK, Boudou A (2007) Dynamics of diatom colonization process in some rivers influenced by urban pollution (Hanoi, Vietnam). Ecol Indic 7:839-851

> Freda J, Dunson WA (1985) The influence of external cation concentration on the hatching of amphibian embryos in water of low pH. Can J Zool 63:2649-2656

Gulis V, Ferreira V, Graça MAS (2006) Stimulation of leaf litter decomposition and associated fungi and invertebrates by moderate eutrophication: implications for stream assessment. Freshw Biol 51:1655-1669

> Gutknecht JLM, Goodman RM, Balser TC (2006) Linking soil process and microbial ecology in freshwater wetland ecosystems. Plant Soil 289:17-34

Hugo S, van Rensburg BJ (2008) The maintenance of a positive spatial correlation between South African bird species richness and human population density. Glob Ecol Biogeogr 17:611-621

Janse I, Bok J, Zwart G (2004) A simple remedy against artifactual double bands in denaturing gradient gel electrophoresis. J Microbiol Methods 57:279-281

Jumpponen A, Jones KL (2009) Massively parallel 454 sequencing indicates hyperdiverse fungal communities in temperate Quercus macrocarpa phyllosphere. New Phytol 184:438-448

Karraker NE, Gibbs JP, Vonesh JR (2008) Impacts of road deicing salt on the demography of vernal pool-breeding amphibians. Ecol Appl 18:724-734

Kinzig AP, Pacala SW, Tilman D (eds) (2001) The functional consequences of biodiversity. Princeton University Press, Princeton, NJ

Kotilainen T, Haimi J, Tegelberg R, Julkunen-Titto R, Vapaavuori E, Aphalo PJ (2009) Solar ultraviolet radiation alters alder and birch litter chemistry that in turn affects decomposers and soil respiration. Oecologia 161:719-728

Laird M (1988) The natural history of larval mosquito habitats. Academic Press, New York, NY

Laposata MM, Dunson WA (1998) Effects of boron and nitrate on hatching success of amphibian eggs. Arch Environ Contam Toxicol 35:615-619

Li SN, Wang GX, Deng W, Hu YM, Hu WW (2009) Influence of hydrology process on wetland landscape pattern: a case study in the Yellow River Delta. Ecol Eng 35:1719-1726

Liu BR, Jia, GM, Chen J, Wang G (2006) A review of methods for studying microbial diversity in soils. Pedosphere 16: 18-24

Loreau M, Naeem S, Inchausti P (eds) (2002) Biodiversity and ecosystem functioning. Oxford University Press, Oxford

$>$ Luck GW (2007) A review of the relationships between human population density and biodiversity. Biol Rev Camb Philos Soc 82:607-645
McArthur JV (2006) Microbial ecology: an evolutionary approach. Elsevier, Burlington, MA

McCune B, Grace JB (2002) Analysis of ecological communities. MjM Software Design, Gleneden Beach, OR

McDonnell MJ, Pickett STA (1990) Ecosystem structure and function along urban-rural gradients: an unexploited opportunity for ecology. Ecology 71:1232-1237

Medeiros AO, Pascoal C, Graca MAS (2009) Diversity and activity of aquatic fungi under low oxygen conditions. Freshw Biol 54:142-149

> Miserendino ML, Brand C, Di Prinzio CY (2008) Assessing urban impacts on water quality, benthic communities and fish in streams of the Andes Mountains, Patagonia (Argentina). Water Air Soil Pollut 194:91-110

> Morin PJ, McGrady-Steed J (2004) Biodiversity and ecosystem functioning in aquatic microbial systems: a new analysis of temporal variation and species richness-predictability relations. Oikos 104:458-466

Morris SJ, Blackwood CB (2007) The ecology of soil organisms. In: Paul EA (ed) Soil microbiology, ecology, and biochemistry, 3rd edn. Academic Press, Burlington, MA, p 195-229

Ndaw SM, Gama-Rodrigues AC, Gama-Rodrigues EF, Sales KRN, Rosado AS (2009) Relationships between bacterial diversity, microbial biomass, and litter quality in soils under different plant covers in northern Rio de Janeiro State, Brazil. Can J Microbiol 55:1089-1095

Nübel U, Garcia-Pichel F, Muyzer G (1999) PCR primers to amplify 16S rRNA genes from cyanobacteria. Appl Environ Microbiol 63:3327-3332

Ochimaru T, Fukuda K (2007) Changes in fungal communities in evergreen broad-leaved forests across a gradient of urban to rural areas in Japan. Can J Res 37:247-258

Podrabsky JE, Hrbek T, Hand SC (1997) Physical and chemical characteristics of ephemeral pond habitats in the Maracaibo basin and Llanos region of Venezuela. Hydrobiologia 362:67-77

Stone JS (1992) Vernal pools in Massachusetts: aerial photographic identification, biological and physiographic characteristics, and state certification criteria. MS thesis, University of Massachusetts, Amherst, MA

Van Hannen EJ, Zwart G, van Agterveld MP, Gons HJ, Ebert J, Laanbroek HJ (1999) Changes in bacterial and eukaryotic community structure after mass lysis of filamentous cyanobacteria associated with viruses. Appl Environ Microbiol 65:795-801

Verb RG, Casamatta DA, Vis ML (2001) Effects of different vegetative substrates on algal composition in vernal mesocosms. Hydrobiologia 455:111-120

Webster J (1992) Anamorph-teleomorph relationships. In: Bärlocher F (ed) The ecology of aquatic hyphomycetes. Springer, Berlin, p 99-177

Wetzel RG (2001) Limnology: lake and river ecosystems, 3rd edn. Academic Press, San Diego, CA

Wierenga PJ, Nielsen DR, Hagan RM (1969) Thermal properties of soil based upon field and laboratory measurements. Soil Sci Soc Am J 33:354-360

Williams DD (2006) The biology of temporary waters. Oxford University Press, Oxford

Zar JH (1999) Biostatistical analysis, 4th edn. Prentice Hall, Upper Saddle River, NJ 
Appendix 1. Distance of each pool to the nearest urban area, as determined with ArcGIS ${ }^{\circledR}$, version 9.3 (ESRI) and 1992 United States Geological Survey land use maps

\begin{tabular}{|lccc|}
\hline \multirow{2}{*}{ Sub-watershed } & \multicolumn{4}{c|}{ Distance to nearest urban area (m) } \\
& Pool 1 & Pool 2 & Pool 3 \\
\hline SW1 & 283.46 & 333.84 & 513.73 \\
SW2 & 560.32 & 697.77 & 776.65 \\
SW3 & 377.63 & 355.65 & 176.40 \\
SW4 & 108.88 & 173.80 & 247.32 \\
SW5 & 234.14 & 245.39 & 268.78 \\
SW6 & 57.75 & 52.82 & 65.38 \\
SW7 & 42.74 & 22.74 & 38.79 \\
SW8 & 11.89 & 16.04 & $0^{\mathrm{a}}$ \\
SW9 & 42.09 & 55.58 & 104.75 \\
SW10 & 9.90 & 28.07 & 61.16 \\
apool located within the 30 $\times 30 \mathrm{~m}$ area that was classified \\
as urban, even though it was found in a forested area \\
\hline \multicolumn{4}{l}{} \\
\hline
\end{tabular}

Editorial responsibility: Urania Christaki, Wimereux, France
Submitted: February 2, 2010; Accepted: June 8, 2010

Proofs received from author(s): November 5, 2010 